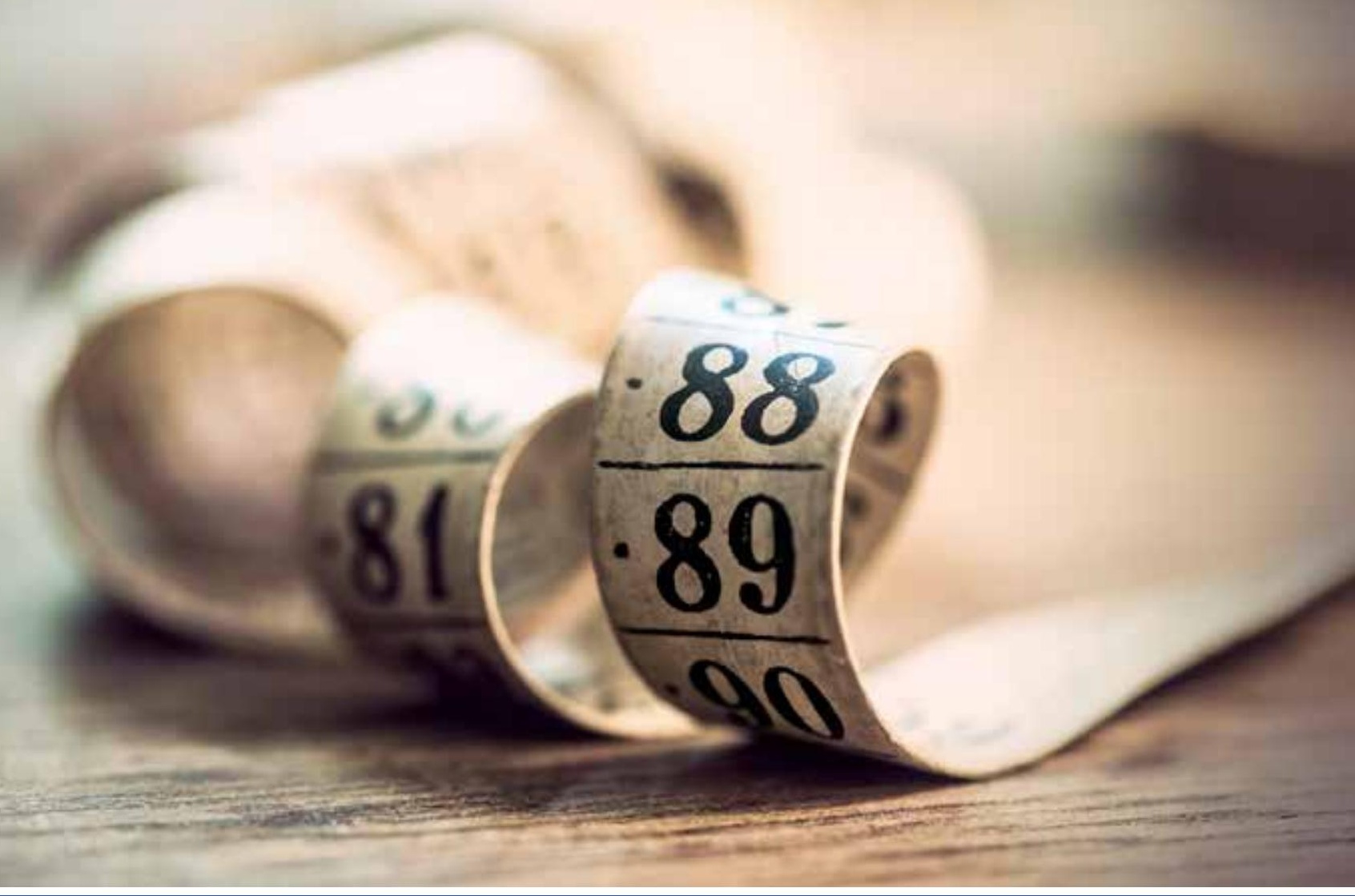

\title{
MEASURING PROGRESS IN ATTAINING TARGETS
}

This chapter focuses on data disaggregation: what it tells us about where we should focus our efforts and what the possibilities are for collecting and using disaggregated data

- Of the 17 Sustainable Development Goals (SDGs), 12 contain indicators that are highly relevant for nutrition. This means that those pushing for nutrition accountability should focus their efforts well beyond SDG 2.

- Disaggregated national data identify subgroups that are often more likely to be malnourished. For example, mothers age 18 or younger are more likely to have stunted children, and children are less likely to be stunted if their mothers have secondary schooling. In many countries, even the wealthiest quintile sees stunting rates of 20 percent and greater.

- Subnational data can help target nutrition spending where it is most needed. The data show wide variations in stunting within countries, with many subnational regions having stunting rates three times higher than the region with the lowest stunting rate.

- The supply of more disaggregated data is constrained by demand, capacity, context, and cost. Some countries are exploring measuring priority indicators closer to the ground and measuring a broader array of indicators at a regional level. Others are looking at combining different surveys to identify trends and target interventions.

- Nearly 60 million people are displaced by conflict, but there are limited data on their access to services or their nutrition status. They are usually absent from national nutrition plans.

- The prevalence of stunting and wasting is higher in the 50 countries classified by the Organisation for Economic Co-operation and Development as "fragile states." We do not know enough about trends in malnutrition in these states, so we cannot tackle this challenge as effectively as we might. 


\title{
TO GUIDE, TRACK, AND LEARN FROM OUR EFFORTS TO REDUCE MALNUTRITION, WE REQUIRE CREDIBLE, TIMELY, AND USEFUL DATA ON NUTRITION OUTCOMES AND INPUTS. IN THE ERA
}

\author{
of the Millennium Development Goals (MDGs), the amount of data available to assess
}

progress in development grew rapidly through formal surveys, administrative data, civil registration, and mobile telephones (United Nations 2014b; World Bank and WHO 2014).

As we enter the era of the Sustainable Development Goals (SDGs), the adoption of these goals has already sparked a great deal of discussion on the breadth and depth of data needed for a data revolution for development (for example, World Bank 2015b). In the nutrition context, several new reports-for example, IFPRI (2014, 2015a); Global Panel on Agriculture and Food Systems for Nutrition (2015) —and initiatives have started to look at these issues. They are building support for open access (such as the Global Open Data for Agriculture and Nutrition [GODAN] initiative), capacity building around metrics and methods (such as Innovative Methods and Metrics for Agriculture and Nutrition Actions [IMMANA]), data reuse and interoperability (for example, SDG2 Accountability), and the use of new technologies (for example, mNutrition).

The focus of this chapter is primarily on data disaggregation. We choose this part of the nutrition data terrain for several reasons. As Chapter 1 stated, we need to be clear about whom SMART (specific, measurable, achievable, relevant, and time bound) commitments need to focus on. This means looking beyond national averages. In addition, the SDG challenge is to move toward zero prevalence of malnutrition (for example, Goal 2.2, “By 2030 end all forms of malnutrition"). This means improving the nutrition status of all groups, no matter how excluded or marginal they are. So we ask, what are the possibilities

FIGURE 8.1 Number of Sustainable Development Goals indicators that are highly relevant for nutrition, by goal

Number of indicators highly relevant to nutrition
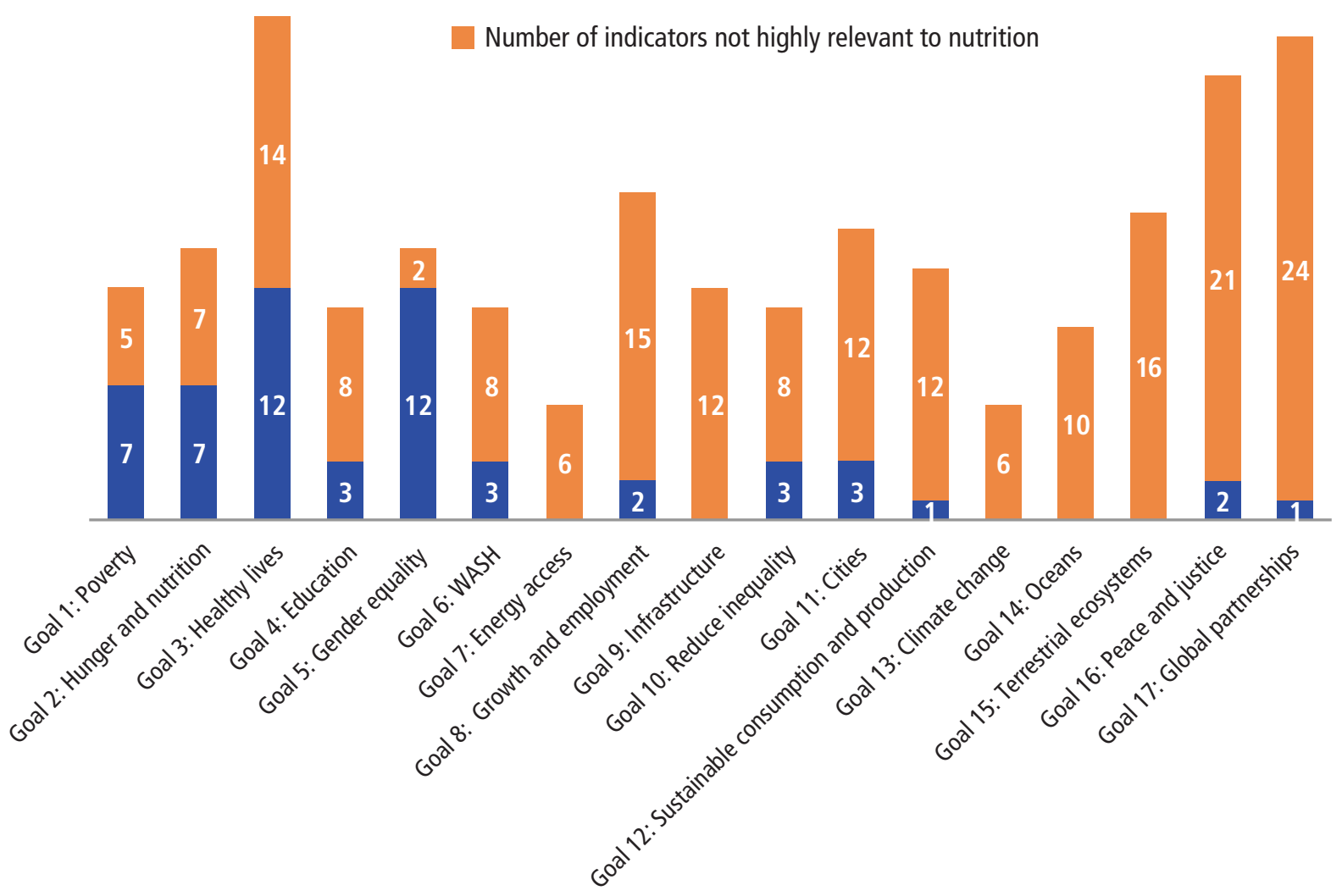

Source: Authors. 


\section{FIGURE 8.2 Nutrition-relevant SDG indicators}

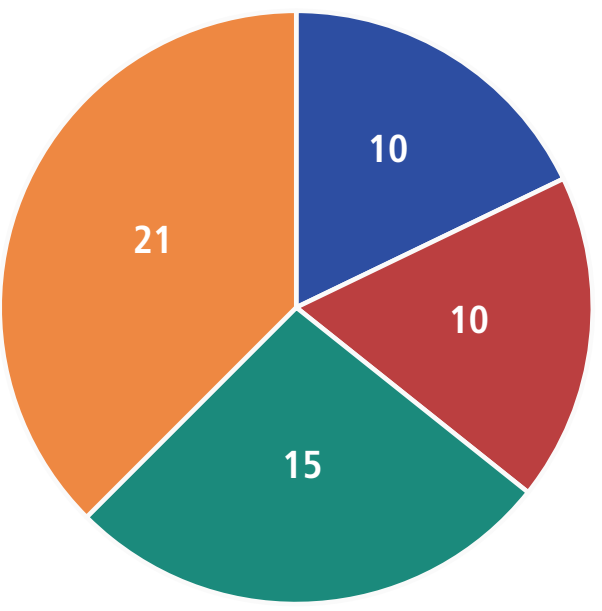

Source: Authors.

Note: DHS = Demographic and Health Survey.
Indicators typically included in DHS-type household surveys (only households with children under $3-5$ years

Indicators that could be added to DHS surveys

Indicators collected from other types of household surveys

Indicators collected from non-household survey sources for disaggregating existing data? And what other options are there for estimating nutrition status at very disaggregated levels? We pay attention to the costs as well as the benefits of disaggregating data. We also pay particular attention to our ability to monitor the nutrition status of one highly vulnerable group-people displaced by conflict-whose numbers have grown rapidly in the past year to 60 million worldwide.

But before looking in depth at disaggregated data as a way of promoting accountability to various vulnerable populations, we review the breadth of indicators that the SDGs encourage us to bring to bear when tracking nutrition outcomes and inputs at all levels.

\section{NUTRITION-RELEVANT INDICATORS IN THE SDGS}

When thinking about the relevance of the SDGs for nutrition, it is tempting to look only in SDG 2 ("End hunger, achieve food security and improved nutrition, and promote sustainable agriculture") for indicators that document nutrition outcomes and inputs. Indeed SDG 2 includes three of the World Health Assembly indicators for undernutrition: stunting, wasting, and overweight among children under 5. However, the SDGs offer many more accountability opportunities to those who want to accelerate nutrition improvements.

An analysis of the nutrition relevance of all 242 indicators proposed for the 17 goals (online Appendix 8) identified 53 indicators that serve as inputs to nutrition (of varying proximity) and 3 that help describe the nutrition situation: 56 in total. The distribution of these 56 indicators by the different sustainable development goals is described in Figure 8.1. Note that SDG 2 contains only 7 of the 56 indicators. It is important to note that others will make their own determination of what should be in the broader SDG nutrition set. In fact, once the SDG indicator list is fully settled, the nutrition community should develop a consensus around the nutrition indicators that should be tracked most closely. The new Health Data Collaborative (2016) with its 100 core health indicators (12 of which are nutrition outcomes and practices that are listed as "risk factors") could prove to be a useful model for the nutrition community to follow in establishing a consensus set.

The SDGs represent a rich opportunity to strengthen accountability in nutrition. That opportunity needs to be taken. Countries need to identify their own broad set of nutrition SDG indicators in the context of national-level processes for strengthening nutrition plans, setting national targets, and establishing capacity to assess progress toward meeting these targets.

Data on the SDG nutrition indicators will come from a variety of sources. Some will be found in the main sources of nutrition data-the Demographic and Health Surveys (DHSs) and Multiple Indicator Cluster Surveys (MICSs)—but these surveys cannot necessarily be relied upon to cover many additional indicators.

Figure 8.2 allocates the 56 indicators in Figure 8.1 into four categories: those that (1) are typically included in DHSs, (2) could be added to DHSs, (3) are collected by 


\section{PANEL 8.1 PERU CONTINUOUS DHS CASE STUDY}

\section{MONICA KOTHARI AND SHEA RUTSTEIN}

Deru was the first country to undertake the Continuous Demographic and Health Survey (Continuous-DHS). The DHS is identified as a continuous survey (CS) when it is undertaken on an annual basis. This CS replaced the standard DHS in Peru, which had been conducted every three to five years. The CS responded to two of Peru's expressed needs. First, the country needed to meet an increasing demand to have data available more frequently than the typical five-year interval between standard DHSs in order to more effectively monitor progress in population and health programs. Second, it needed to institutionalize the capacity to conduct DHSs.

The Peru CS started with 6,000 sample households in 2004 (2004-2007 cycle) and has now expanded to a sample of about 40,000 households. In the 2008 round, the government of Peru wanted to increase the sample size to get estimates at the subnational (department) level every year. The Child Nutrition Initiative, started under President Alan Garcia, required anthropometric data from every department in 2008. Around the same time, the Ministry of Finance started a "governing by results" framework, which required annual department-level data for implementation. To support this data need, Peru's Congress approved and continues to approve a line item of about $\$ 2.5$ million to conduct the CS every year. Hence over time there has been a strong political commitment to support data collection and reporting from the Office of the President down to lower political offices.

The Peru CS is currently in its 11 th cycle. There is a permanent CS unit established within the National Institute of Statistics and Information (INEI), and INEI has several staff members who are government employees dedicated full time to the survey. This unit has experienced very low staff turnover.

The financial benefits of institutionalizing DHS within the country are clear: the country is no longer dependent on unpredictable donor funding and priorities. In addition, institutionalization allows for retaining full-time staff dedicated to the DHS, rather than spending resources on training and retraining short-term staff every few years. Furthermore, the CS has the potential to yield data of higher quality, since permanent staff would have a greater stake in adhering to performance standards than would short-term staff. Data quality is also assumed to be higher with the CS model because the model allows for timely identification and correction of errors. Due to the more frequent data collection cycles in the CS model, the CS design can be more flexible and sensitive to users' needs for special information. Moreover, updated data become available more frequently with the CS model.

However, there are also several potential challenges associated with the CS model. Integration of CS into existing organizational infrastructures can be difficult, especially in cases where current staff have little extra time to devote to additional activities. The CS design is more complex and demands more technical support than standard DHS designs. Securing a consistent flow of funding for the CS model may also be difficult. In addition, conducting surveys every year in difficult field settings may result in staff fatigue. Finally, there may be data demands that cannot be easily accommodated within the CS design (Rutstein and Way 2014). other household surveys, and (4) are collected from nonhousehold survey sources. ${ }^{1}$ As Figure 8.2 shows, fewer than one-fifth of the SDG nutrition-relevant indicators are covered in a typical DHS. A similar proportion are covered in MICSs. Clearly SDG nutrition data collection will need to draw on a wide set of sources. Indeed one of the SDG indicators is the proportion of total SDG indicators that are produced at the national level. Thus a good accountability indicator for the nutrition community to track is the proportion of the nutrition-relevant SDG indicators produced at the national level.

Recognizing that many of these SDG indicators do not yet exist, we count only about 15 of the 56 SDG nutrition indicators in the Global Nutrition Report nutrition country profiles, ${ }^{2}$ and we will, accordingly, reassess the nutrition country profiles for the 2017 Global Nutrition Report in light of the SDG indicator set and explore the possibilities for greater alignment between the two.

If the SDG reporting process follows the MDGs, there will be an annual reporting on SDG indicators. Annual collection of data-especially data based on household surveys-is a time-consuming activity. Peru provides a valuable example of the benefits and costs of institutionalizing the annual collection of nutrition survey data (Panel 8.1). ${ }^{3}$ In theory, Peru provides one model of a self-sustained data collection and reporting institution. Realistically, though, as the panel indicates, it has been challenging to find the resources needed to replicate the model elsewhere. 


\section{DISAGGREGATION OF DHS STUNTING DATA}

The preamble of the 2030 Agenda for Sustainable Development, in which world leaders announced the SDGs, states, "We are resolved to free the human race from the tyranny of poverty and want, and to heal and secure our planet. We are determined to take the bold and transformative steps which are urgently needed to shift the world onto a sustainable and resilient path. As we embark on this collective journey, we pledge that no one will be left behind" (United Nations 2015, emphasis added). ${ }^{4}$

This section describes some subnational patterns in stunting rates for DHS datasets. We do this to emphasize the wide variations in malnutrition rates by wealth, education, age of mother at birth, residence, and sex. The data are summarized in Figures 8.3 to 8.7. ${ }^{5}$ The surveys are the most recent disaggregated DHSs available for each country. The analysis benefits from the availability of more recent data than the analyses in Black et al. (2013) and Bredenkamp et al. (2014). In addition, we order the data in different ways to try to gain some new insights.

- Wealth: Figure 8.3a compares stunting rates by lowest and highest wealth quintile. The patterns are similar to those observed in Black et al. (2013). We order the countries by the stunting rate in the highest wealth quintile. As expected, stunting rates are lower in this quintile, yet levels in the wealthiest 20 percent of households can be high (for example, in Timor-Leste, Madagascar, Burundi, Malawi, Niger, and Ethiopia). Many countries have rates of stunting of more than 20 percent for children in the top quintile of household wealth. This is partly because the countries are low income and even households in the top fifth of wealth are quite poor. But it is also because the correlation between income and stunting is not as strong as sometimes thought (Ruel and Alderman 2013). Leaders of the countries on the left-hand side of this figure should not assume that their relatively wealthier households are able to address stunting.

Figure $8.3 \mathrm{~b}$ orders the countries by the size of the gap in stunting prevalence between the highest and lowest wealth quintiles. The existence of a large gap indicates inequality within a country. All countries should strive to ensure equal opportunity of access to good nutrition inputs for all people. Various approaches are outlined in Chopra et al. (2012) for nutrition and health program coverage and in Haddad (2015) for poverty interventions.

- Rural/urban location: Figure 8.4 compares stunting rates for those living in urban with those in rural locations. Again, patterns are similar to those observed in Black et al. (2013). Children in rural settings have higher stunting rates, but in 13 countries even children in urban areas have stunting rates of 30 percent or greater. The figure orders countries by the rural-urban gap, and a number of countries at the left-hand side of the figure are also on the left-hand side of Figure 8.3b, reflecting a similar set of inequalities, manifest this time between rural and urban areas.

- Mother's age at birth: Figure 8.5 displays the stunting prevalence for children under 5 by the age of their mother at their birth. Low age of mother at birth is a risk factor for small birth size (Kozuki et al. 2013). We compare the stunting prevalence of children under 5 with mothers who were less than 18 years of age at the time of birth, with the stunting prevalence of children under 5 with mothers who were 18 years of age or older at the time of birth. For some countries the differences between the two groups are striking. In Ghana and Uganda the differences in stunting prevalence approach 20 percentage points, and for more than half of the countries the gap is greater than 5 percentage points.

- Mother's education: We know from Chapter 1 that women's empowerment is key to ending malnutrition and that education is an important driver of empowerment. Figure 8.6 contrasts stunting rates by the extremes of the mother's education level (high levelthat is, beyond secondary school-versus no formal education). The differences in stunting rates between the two extremes of education are bigger than the wealth group differences in Figures 8.3, emphasizing the high value of girls' education for the nutrition status of their children. But having a level of education beyond secondary school is no guarantee against high stunting rates: eight countries have stunting rates of 20 percent or greater for mothers with higher than a secondary level of schooling.

- Sex of child: Figure 8.7 presents stunting data by the sex of the child. In nearly all countries male stunting rates are higher than female rates, but the differences are small relative to other stratifiers. ${ }^{6}$ As Panel 8.2 notes, while there are no major gender disparities in rates of stunting under the age of 5, as boys and girls get older the disparities become more apparent. There are no major disparities in under-5 overweight (Figure 8.8) or exclusive breastfeeding rates (Figure 8.9) by sex of child.

Household surveys can be used to explore and identify differences in outcomes by ethnic group, level of disability, and history of domestic or international displacement. Panel 8.2 highlights results from a recent report that uses 


\section{PANEL 8.2 NUTRITION AND EXCLUSION}

\section{MARIE RUMSBY, KATHERINE RICHARDS, FAIZA SHAHEEN, JONATHAN GLENNIE, AMANDA LENHARDT, AND JOSE MANUEL ROCHE}

$\mathrm{M}$ any countries have shown it is possible to address malnutrition. Yet for millions of children who still suffer because of malnutrition, progress has not been fast enough or equal enough. A recent report (Shaheen et al. 2016) shows how certain groups are being left behind at the start of an era in which the commitment from world leaders is to "leave no one behind."

Our research (including data from Save the Children's GRID' database) shows that children's life chances and health outcomes are lower than average if they are girls, refugees, displaced or disabled, or from a regionally disadvantaged area within a country or an excluded ethnic group. Not only are such children poor, but they are discriminated against and have little or no say in the decisions that affect their lives. Findings include the following:

- Inequalities in stunting between regions within countries are increasing in 52 percent of countries for which we have data (Shaheen et al. 2016).

- In Ghana, Gurma people are more than three-and-a-half times more likely to be stunted than the $\mathrm{Ga}$ and Dangme people. The gap has increased from two times more likely in 2008 (Shaheen et al. 2016).

- In Viet Nam, malnutrition rates are nearly four times higher among children from minority ethnic groups than those from the majority Kinh (GSO 2011).

- A child in the remote North West region of Nigeria—where stunting rates are around 55 percent-is nearly four times more likely to experience malnutrition than a child in the South East region (Shaheen et al. 2016).

- Children with a disability are consistently reported to have a high incidence of malnutrition, stunting, and wasting (AbdAllah et al. 2007). For example, children with cerebral palsy can be up to three times more likely to be underweight than nondisabled children (Tuzun et al. 2013).

What is underlying these statistics?

- Ethnicity: Poor indicators of health and nutrition among disadvantaged ethnic groups are common, especially among indigenous peoples. Commonly reported barriers include lack of sanitation coverage; inequitable income distribution; and poor access to education, as seen in the cases of Brazil (Ferreira et al. 2012) and South Africa (Gradin 2015).

- Disability: Many types of disability can be caused by malnutrition through lack of micronutrients or macronutrients or through exposure to high concentrations of antinutrients - toxins found in food, such as those in poorly processed cassava, that can lead to permanent neurological damage (Groce et al. 2013; Kuper et al. 2014). Disability can also lead to malnutrition through decreased nutrient intake, increased nutrient loss, and need for increased nutrients, which can put children at risk of further complications (Gradin 2015).
- Children on the move: Worldwide displacement of people is now at the highest level ever recorded, with an estimated 59.5 million people (as of 2014) forcibly displaced as a result of persecution, conflict, generalized violence, or human rights violations (UNHCR 2014b). Refugees have a high burden of malnutrition and anemia; treatable noncommunicable diseases, exacerbated by lack of access to regular medication; and infectious diseases, including hepatitis A and B and parasitic diseases (Langlois et al. 2016).

- Gender: Preferential treatment based on gender can result in differing feeding practices and food intake. In Kenya, a strong gender bias in intrahousehold food distribution was found to lead to more girls with malnutrition, stunting, wasting, and infectious diseases (Ndiku et al. 2011). Globally, while there are no major gender disparities in rates of stunting in children under 5 (Shaheen et al. 2016), as boys and girls get older, the disparities become more apparent (Bhutta and Zlotkin 2014)—up to half of all adolescent girls are stunted in some countries (Black et al. 2013). Women are particularly vulnerable to malnutrition because of their high nutrient requirements during pregnancy and lactation and because of gender inequalities in poverty (Delisle 2008). In some settings, high rates of adolescent pregnancy and early marriage can further compound these disparities. 
DHS and MICS data for this purpose. The panel authors argue that accountability to excluded groups under the SDGs must be far more comprehensive than it has been under the MDGs. Governments have a human responsibility to ensure that they collect sufficiently disaggregated and transparent information to understand which groups may be excluded and how they are excluded, in order to design policy and program solutions that include all social and economic groups, and remedy such exclusion in any given context.

\section{FIGURE 8.3 Stunting prevalence in children under 5 by wealth quintile}

\section{A. ORDERED BY STUNTING PREVALENCE IN THE HIGHEST WEALTH QUINTILE}

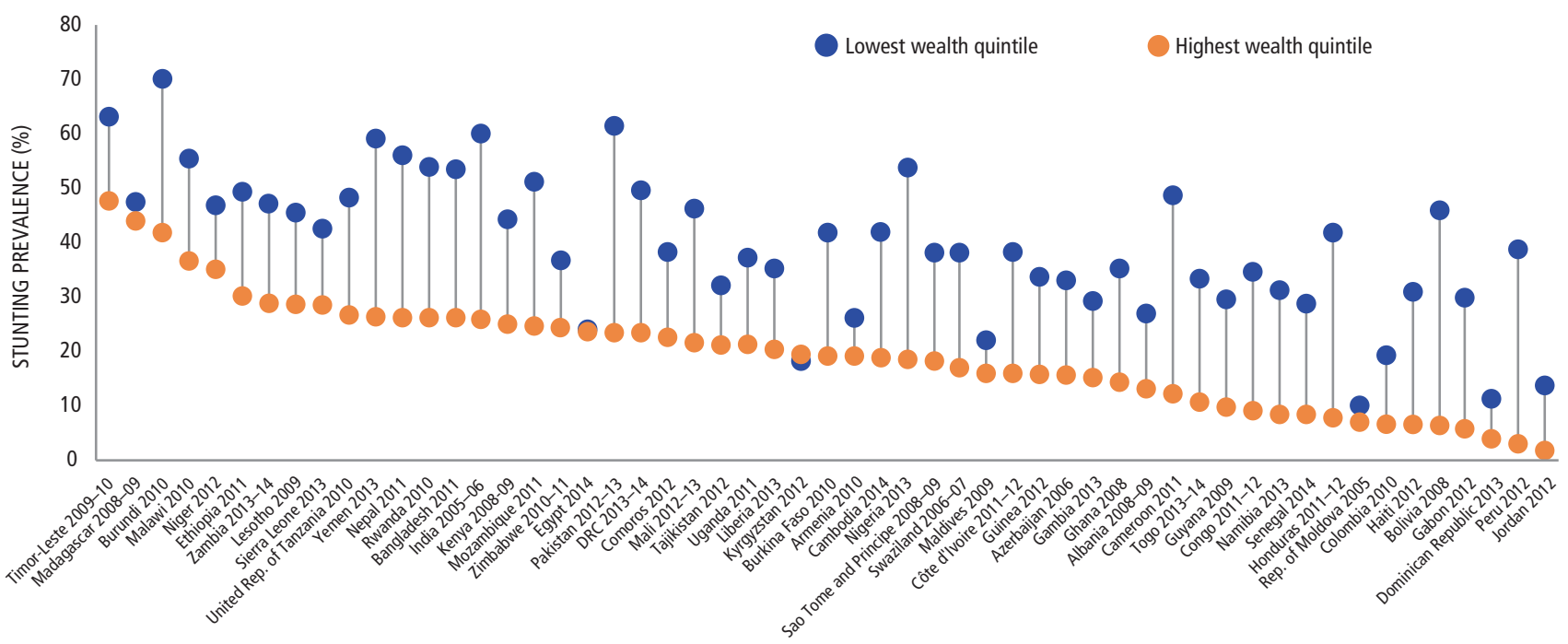

B. ORDERED BY THE SIZE OF THE GAP IN PREVALENCE

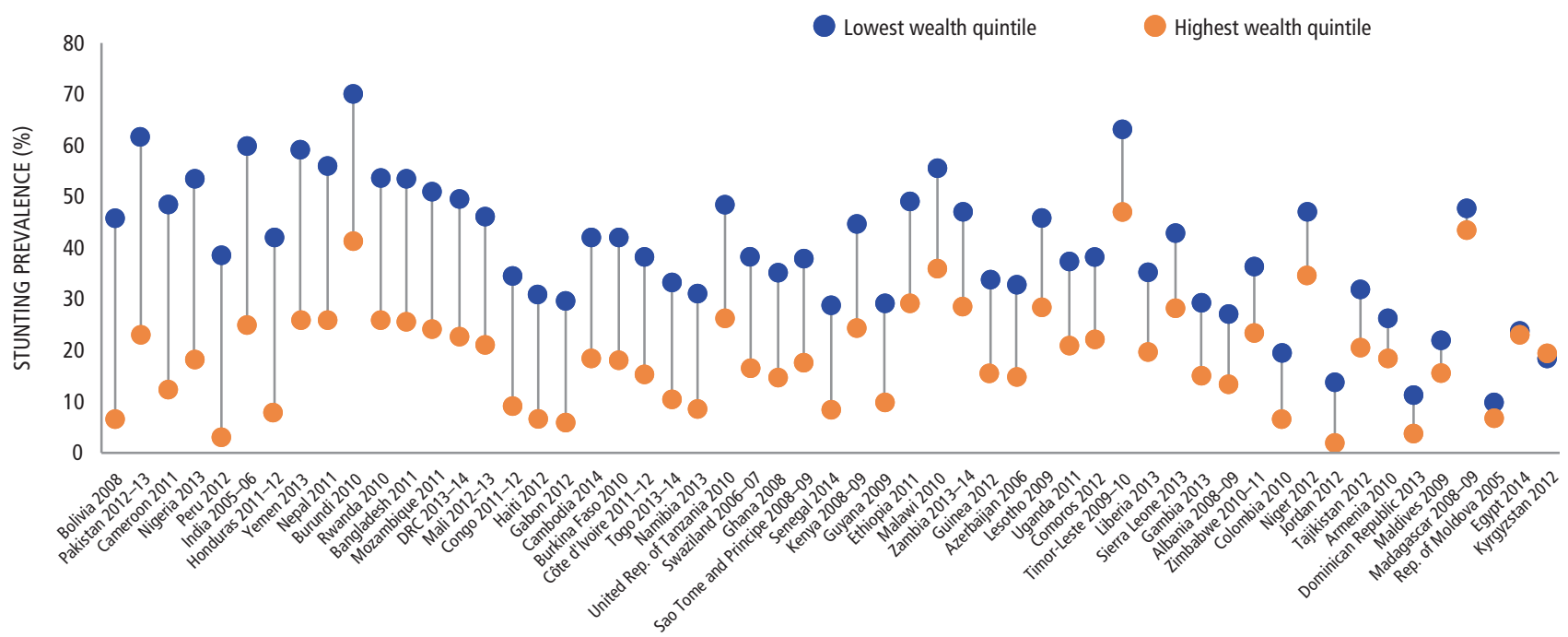

Source: Authors, based on data and analysis by Monica Kothari, Demographic and Health Surveys (DHSs), 2005-2015.

Note: There may be discrepancies from data reported in the DHS reports because of subsequent transformations by the DHS team. All categories of prevalence have $n>50$. DRC $=$ Democratic Republic of the Congo. 
FIGURE 8.4 Stunting prevalence in children under 5, urban or rural, ordered by size of gap

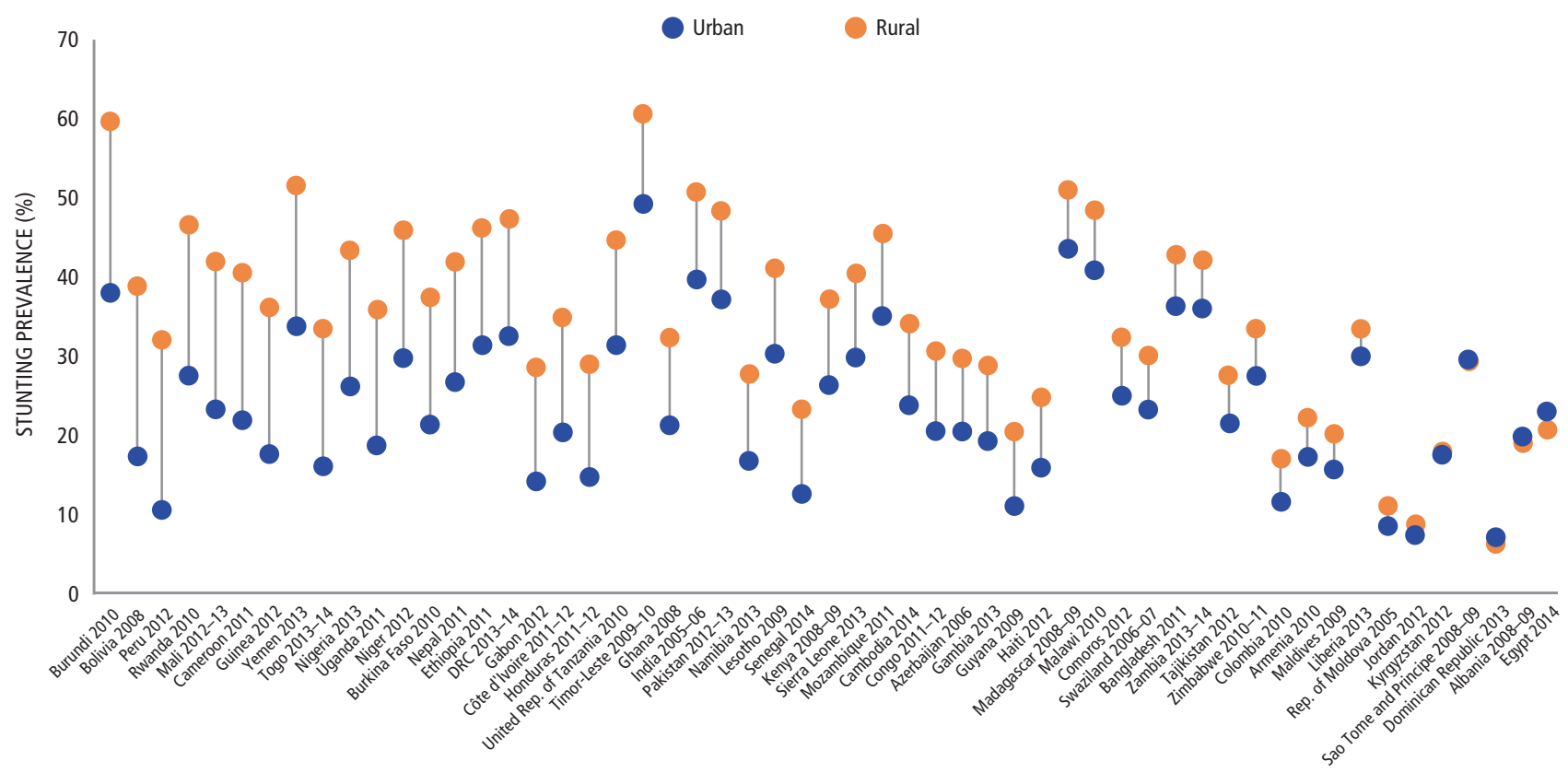

Source: Authors, based on data and analysis by Monica Kothari, Demographic and Health (DHS) surveys, 2005-2014.

Note: There may be discrepancies from data reported in the DHS reports because of subsequent transformations by the DHS team. All categories of prevalence have $n>50$. DRC $=$ Democratic Republic of the Congo.

FIGURE 8.5 Stunting prevalence in children under 5 by age of mother at time of child's birth, ordered by size of gap

Mothers aged $<18$ at time of birth

Mothers aged $\geq 18$ at time of birth

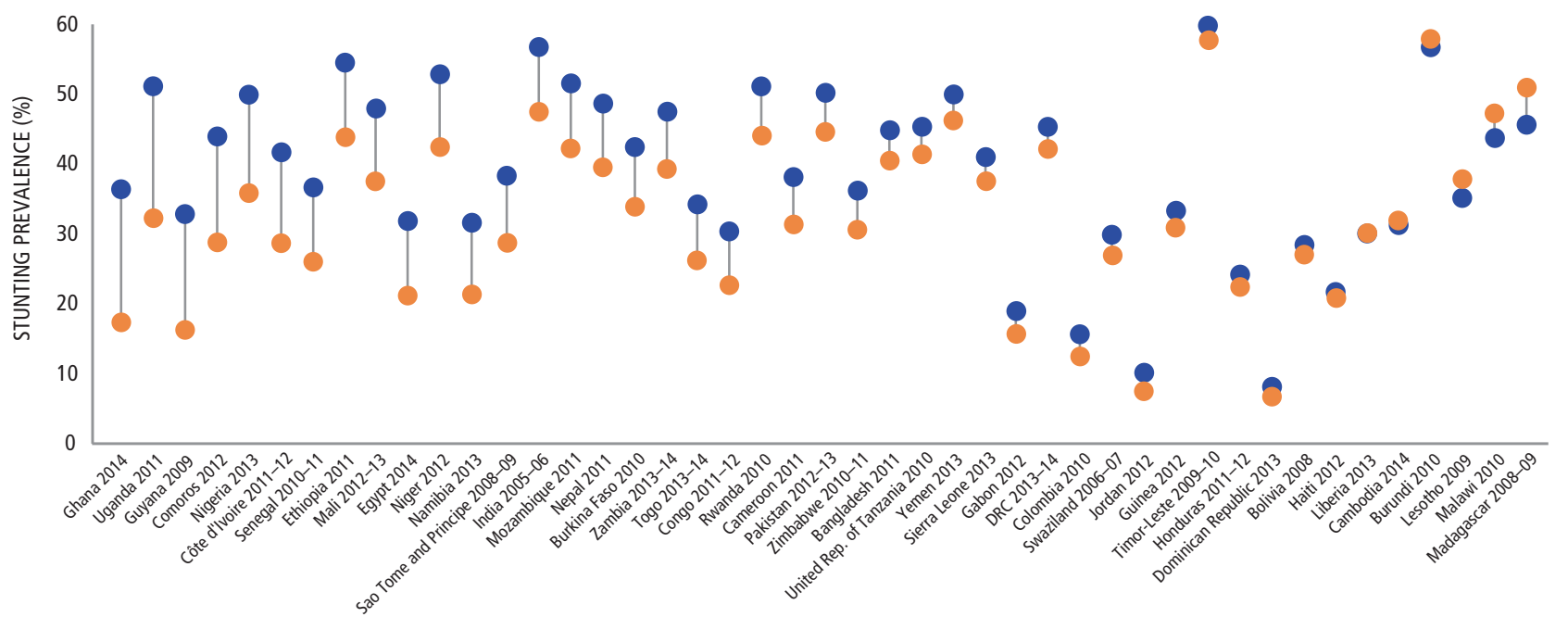

Source: Authors, based on data and analysis by Monica Kothari, Demographic and Health (DHS) surveys, 2005-2014.

Note: There may be discrepancies from data reported in the DHS reports because of subsequent transformations by the DHS team. All categories of prevalence have $n>50$. DRC = Democratic Republic of the Congo. 
FIGURE 8.6 Stunting prevalence in children under 5 by mother's education, ordered by prevalence among children whose mothers have no education

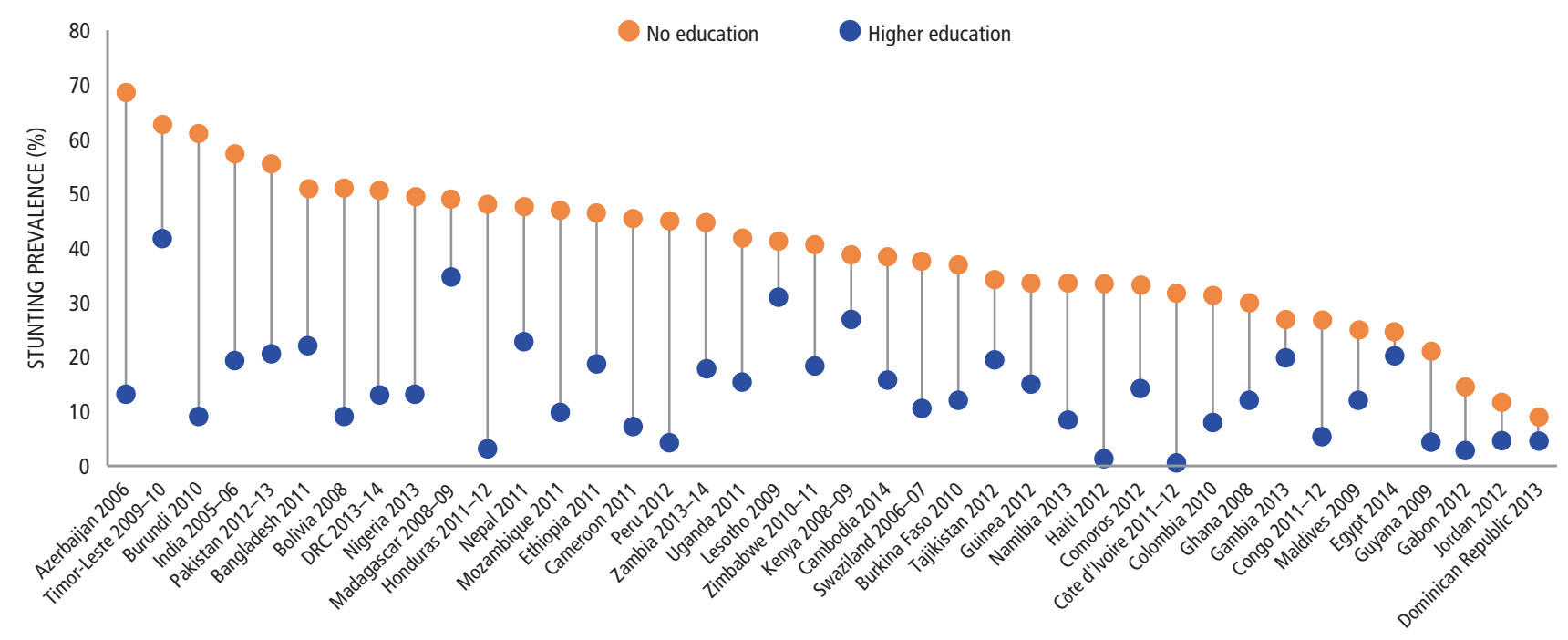

Source: Authors, based on data and analysis by Monica Kothari, Demographic and Health (DHS) surveys, 2005-2014.

Note: There may be discrepancies from data reported in the DHS reports because of subsequent transformations by the DHS team. All categories of prevalence have $n>50$. "Higher education" means higher than secondary school. DRC = Democratic Republic of the Congo.

FIGURE 8.7 Stunting prevalence in children under 5 by sex, ordered by size of gap

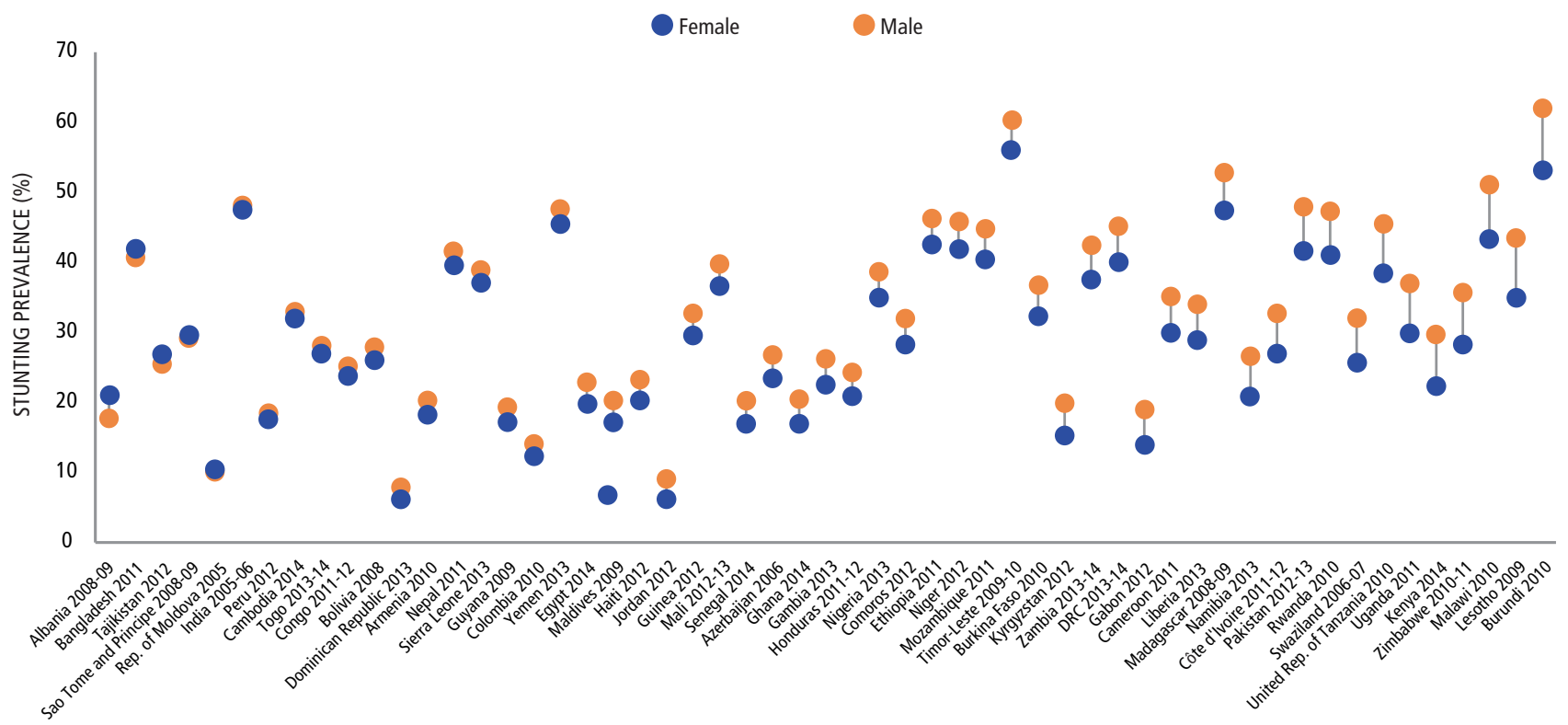

Source: Authors, based on data and analysis by Monica Kothari, Demographic and Health (DHS) surveys, 2005-2014

Note: There may be discrepancies from data reported in the DHS reports because of subsequent transformations by the DHS team. All categories of prevalence have $n>50$. DRC = Democratic Republic of the Congo. 
FIGURE 8.8 Overweight status of children under 5 by sex, ordered by female-male gap

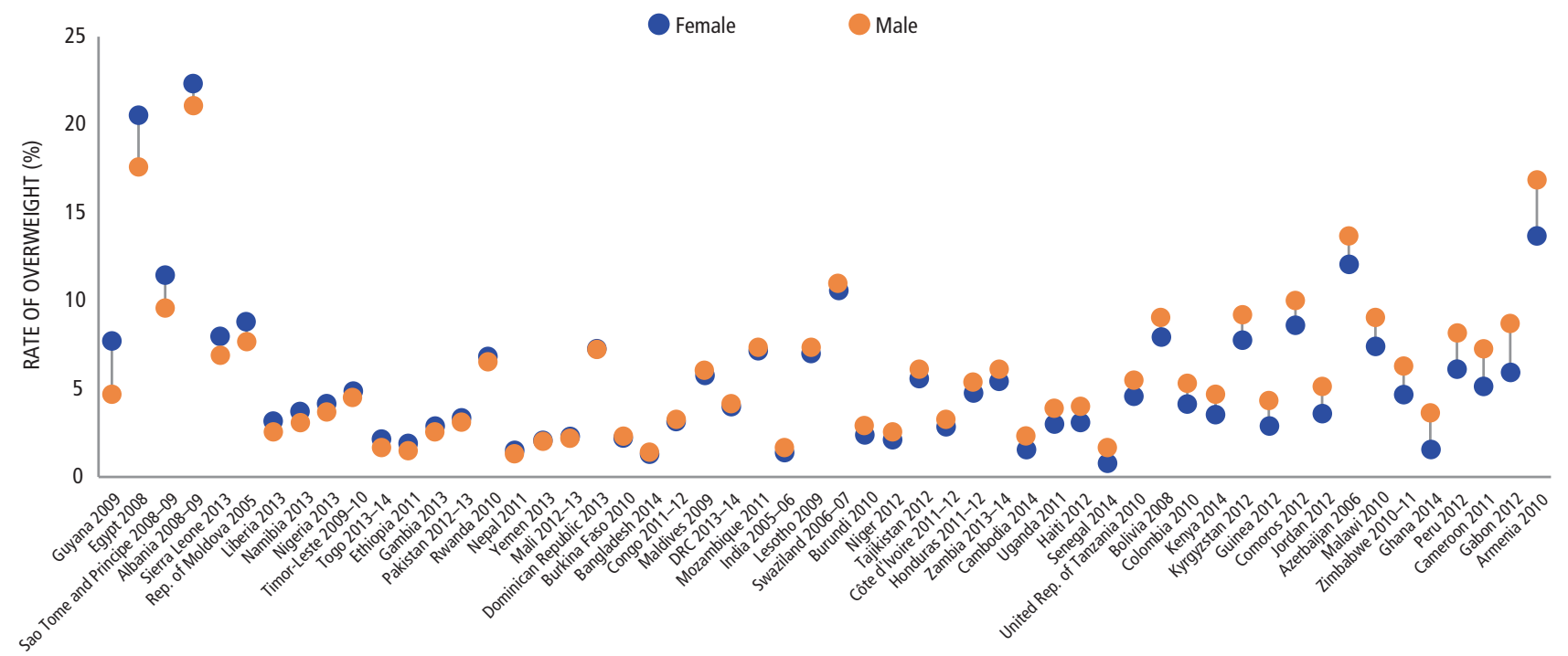

Source: : Authors, based on data and analysis by Monica Kothari, Demographic and Health Surveys (DHSs), 2005-2014.

Note: There may be discrepancies from data reported in the DHS reports because of subsequent transformations by the DHS team. All categories of prevalence have $n>50$. DRC $=$ Democratic Republic of the Congo.

FIGURE 8.9 Exclusive breastfeeding by sex, ordered by female-male gap

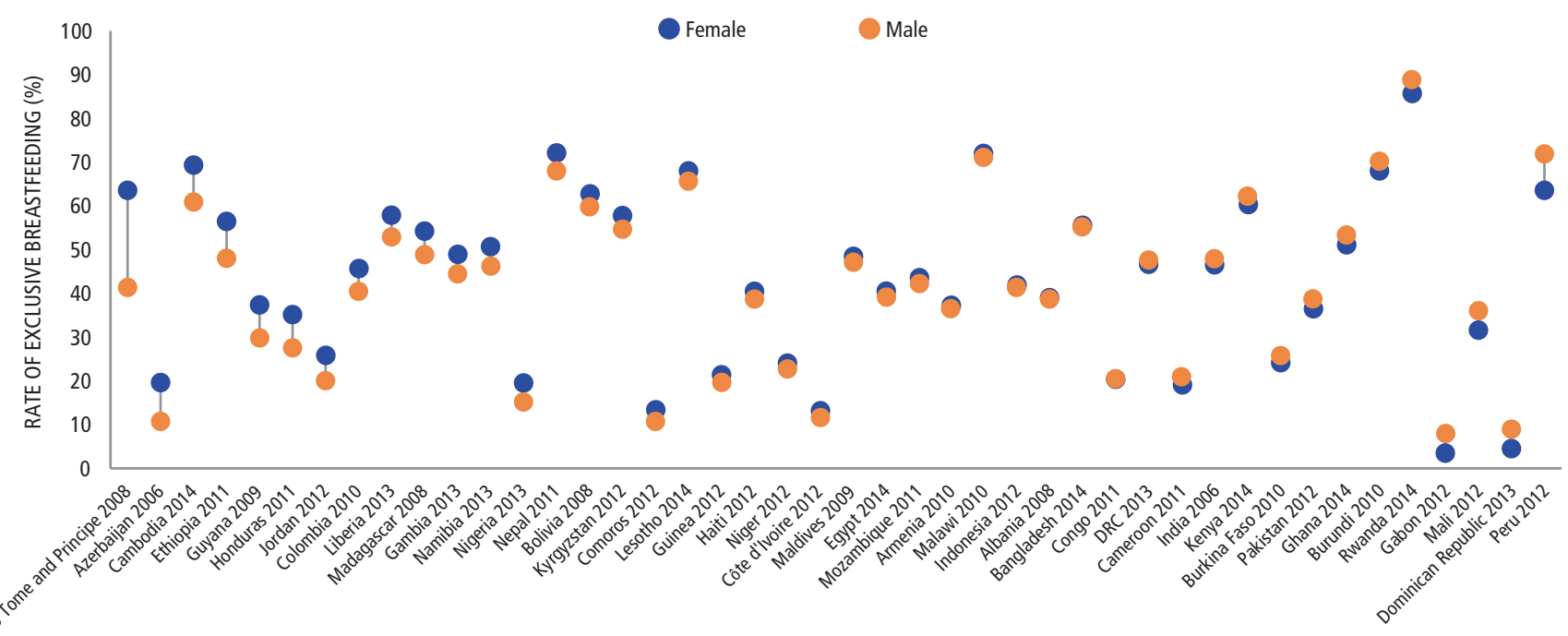

Source: Authors, based on data and analysis by Monica Kothari, Demographic and Health Surveys (DHSs), 2005-2014.

Note: There may be discrepancies from data reported in the DHS reports because of subsequent transformations by the DHS team. All categories of prevalence have $n>50$. DRC = Democratic Republic of the Congo. 


\section{PANEL 8.3 FACTORS TO TAKE INTO ACCOUNT WHEN CONSIDERING WHETHER TO COLLECT GEOGRAPHICALLY DISAGGREGATED DATA}

\section{MONICA KOTHARI, FRED ARNOLD, BERNARD BARRERE, ANN WAY, ANNE CROSS, RUILIN REN, JOY FISHEL, AND SRI POEDJASTOETI}

\section{Demand}

While national stakeholders might be interested in subnational data, are the subnational units from which the data would be collected prepared to use and act on the information? Are they making their own policy and program design decisions? If so, are the decisions informed by data at the subnational level really going to be different from the program or policy decisions that would be made if only regional data were available?

\section{Capacity}

The decision to obtain data at the subnational level is country specific. In countries with weak statistical infrastructure (for example, those that cannot independently manage normal Demographic and Health Survey [DHS] samples, which are already large), it would be challenging to expand surveys to obtain estimates below the regional level. Asian, Latin American, and Caribbean countries with strong implementing agencies are in the best position to carry out expanded surveys. However, even in those settings, it is debatable whether the benefits are worth the monetary costs and the risk of compromising the survey data quality. Increasing sample size means increasing the cost, but more important, it means increasing the number of teams, and the number of people to train and to supervise the survey. It has been the experience of DHS that the quality of training and data collection may decrease when the survey size increases.

\section{Context}

Trends in lower-level estimates for some indicators are sometimes counterintuitive because of the large confidence intervals around the estimates. These unexpected changes over time may be questioned and may cause considerable political fallout. Alternative data collection options should be explored to fulfill country-specific data needs. Data sources like routine health management information systems should be able to fill some data gaps by reporting on public-sector nutrition intervention coverage at frequent intervals. Largescale surveys should continue to provide the higher-level nutrition prevalence and coverage estimates for the general population that are comparable across countries and time.

\section{Costs}

The costs for large-scale household surveys are mainly related to the number of sampling domains for which information is desired. The required sample size for a survey that is representative at an administrative domain level depends on the number of administrative domains there are in the country. The general rule of thumb for determining the sample size for a large-scale survey like the DHS is that about 800-1,000 women need to be interviewed in each sample domain to get reliable estimates of the total fertility rate and the infant mortality rate. Many nutrition indicators included in a DHS usually require smaller sample sizes to obtain reasonably precise estimates at the domain level. If one wants to double the number of domains, the sample size also needs to be doubled, which substantially increases the survey cost.

\section{WEIGHING THE BENEFITS AND COSTS OF GEOGRAPHICALLY DISAGGREGATED DATA}

The demand for nutrition data at the level of the subnational administrative unit is increasing. Policy makers need it for guiding action to get to zero levels of malnutrition, subnational administrators need it as the responsibility for nutrition program implementation gets decentralized, businesses need it to identify opportunities, external donors need it to target their interventions, and those in civil society need it to promote accountability for the most vulnerable.
This demand for more fine-grained data is based on the assumption that there are wide variations in nutrition status by region. As Figure 8.10 highlights, this assumption is well founded. For many countries, the figure illustrates the wide differences between administrative regions with the highest and lowest stunting rates. For example, the median ratio between the highest and lowest stunting rates is 2.96 and the range is 1.06 to 17.59 . These differences reflect a wide range of historical, cultural, geographic, economic, and political differences in opportunity that will not be narrowed quickly. Nevertheless, awareness of these vast differences is essential for national plans of action and for the effective allocation of resources. 

by size of gap

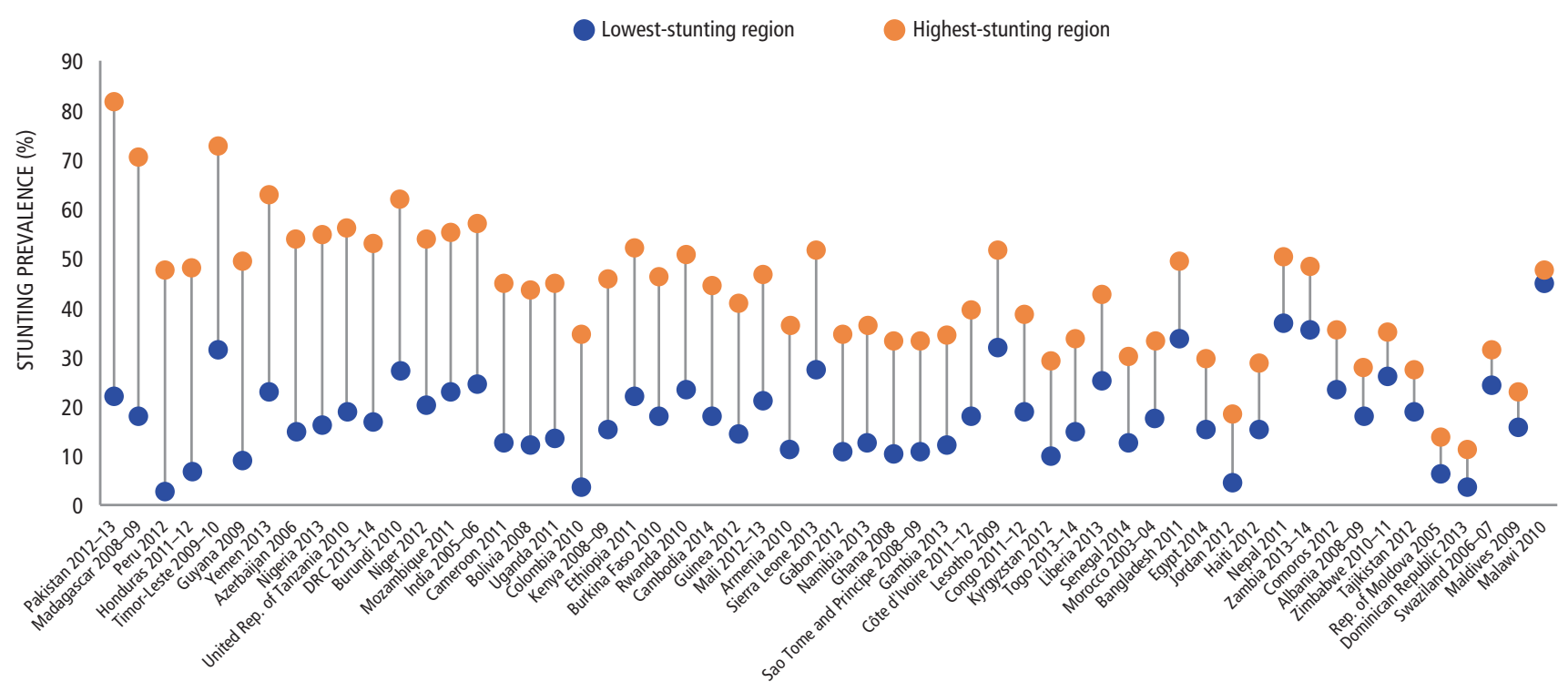

Source: Authors, based on data and analysis by Monica Kothari, Demographic and Health Surveys (DHSs), 2005-2014.

Note: There may be discrepancies from data reported in the DHS reports because of subsequent transformations by the DHS team. All categories of prevalence have $n>50$. DRC = Democratic Republic of the Congo.

If the demand for more disaggregated data is strong, its availability is quite limited. For example, so far the DHS team has been involved in only two national surveys that have collected data at the lowest administrative level: the 2014 Kenya DHS and the 2015-2016 India National Family Health Survey. In Kenya, earlier DHSs provided data for each of the eight provinces (seven plus Nairobi) because the next administrative level down was the district, and there were too many districts-more than 80-to disaggregate the survey data by district. In 2010, however, Kenya approved a new constitution, which organized the country into 47 counties. In the most recent DHS, the survey sample was increased to allow estimates to be made at the new lowest administrative unit level-the county level. In India, for the 2015-2016 National Family Health Survey, the national government stipulated that separate estimates were needed for each of the 640 districts in India at the time of the 2011 census.

Based on the experiences of the DHS team, the supply of more disaggregated data is constrained by certain key factors: demand, capacity, context, and costs (Panel 8.3).

Are there cost-effective options to obtain subnational data? ${ }^{7}$ For some indicators, like fertility, mortality, and vaccination coverage, DHS and similar surveys are providing data that might alternatively be covered through routine surveillance systems, if those systems produced complete, accurate, and timely data. If high-quality surveillance systems were in place in countries and they covered a high proportion of cases, some of these indicators could be removed from household surveys, but the cost savings of doing so would be only marginal.

Recently, Kenya used two different questionnaires and different subsamples to conduct the DHS. Enumerators measured priority indicators at the district level and then measured a broader array of indicators at a higher, regional level. The India survey is using a similar procedure to measure some indicators at the provincial level and others at only the state level. This could be one cost-effective way to get subnational data without compromising data quality.

In Indonesia, the DHS competes with other national and subnational surveys. DHS is only one of several annual household surveys conducted by the Central Bureau of Statistics. The Ministry of Health's surveys are carried out by each province/regency/municipality. Each of these surveys presents data at the regency/municipality level. In this way, Indonesia has built the internal capacity to conduct surveys and over time has required less technical assistance.

The World Food Programme and DHS, among others, have regularly explored the potential for using small-area estimation techniques that use survey estimates at a higher 


\section{PANEL 8.4 WHY HIGHLY DISAGGREGATED UNDERNUTRITION MAPS ARE VITAL IN THE SUSTAINABLE DEVELOPMENT GOALS ERA}

\section{KURT BURJA, STEPHEN HASLETT, SIEMON HOLLEMA, GEOFF JONES, KAYENAT KABIR, AND CHRISTA RADER}

W hile small-area estimation poverty maps are more and more common, such finely detailed maps for undernutrition are rare. Yet we need such maps for undernutrition. For example, small-area maps for stunting, underweight, and wasting in children under 5 years of age may not correlate closely with those for poverty because different factors influence nutrition outcomes.

Small-area estimation of undernutrition involves combining nutrition surveys like the DHS and MICS with a contemporaneous census (which does not record nutrition outcomes). Common variables, such as household assets, construction materials, and water and sanitation provision, and personal characteristics, such as mother's education and child's age, that are available in both surveys and censuses, are used to develop a statistical relationship with the undernutrition outcomes available only in the DHS/MICS. Then this relationship is used to estimate nutrition for groupings of 20,000 to 30,000 contiguous households based on predictions from the census. Often there is a focus on children younger than 5 . Although the underlying concepts are simple, the modeling is time consuming and requires considerable expertise. Many models need to be considered and tested to find a suitable one. Other complexities include quality of measurement, especially child's height. The resulting maps, based on sound, well-tested models, tend to concur with expert opinion on the location of high and low rates of undernutrition. ${ }^{1}$

The maps and small-area estimates of undernutrition are highly valuable. Generally, no one map is sufficient, but together they give a detailed picture of undernutrition rates and where the largest numbers of undernourished people are. They help guide prioritization and geographic targeting of assistance programs, whether these are based on rates of undernutrition or on the number of undernourished by area.

They are also a common tool for reaching consensus with stakeholders on which geographic areas to prioritize and are useful in predisaster contingency planning and postdisaster needs estimation. Maps can also aid in policy analysis and planning. Examples of these maps for Bangladesh (stunting), Cambodia (stunting), and Nepal (calorie intake) are shown here.

More such maps are needed. The methods are complex, but expertise is available. The Sustainable Development Goals' focus on ending malnutrition calls for detailed geographic information on prevalence and severity to address the problem in the most effective way. Small-area estimation maps of undernutrition can help us do just that.
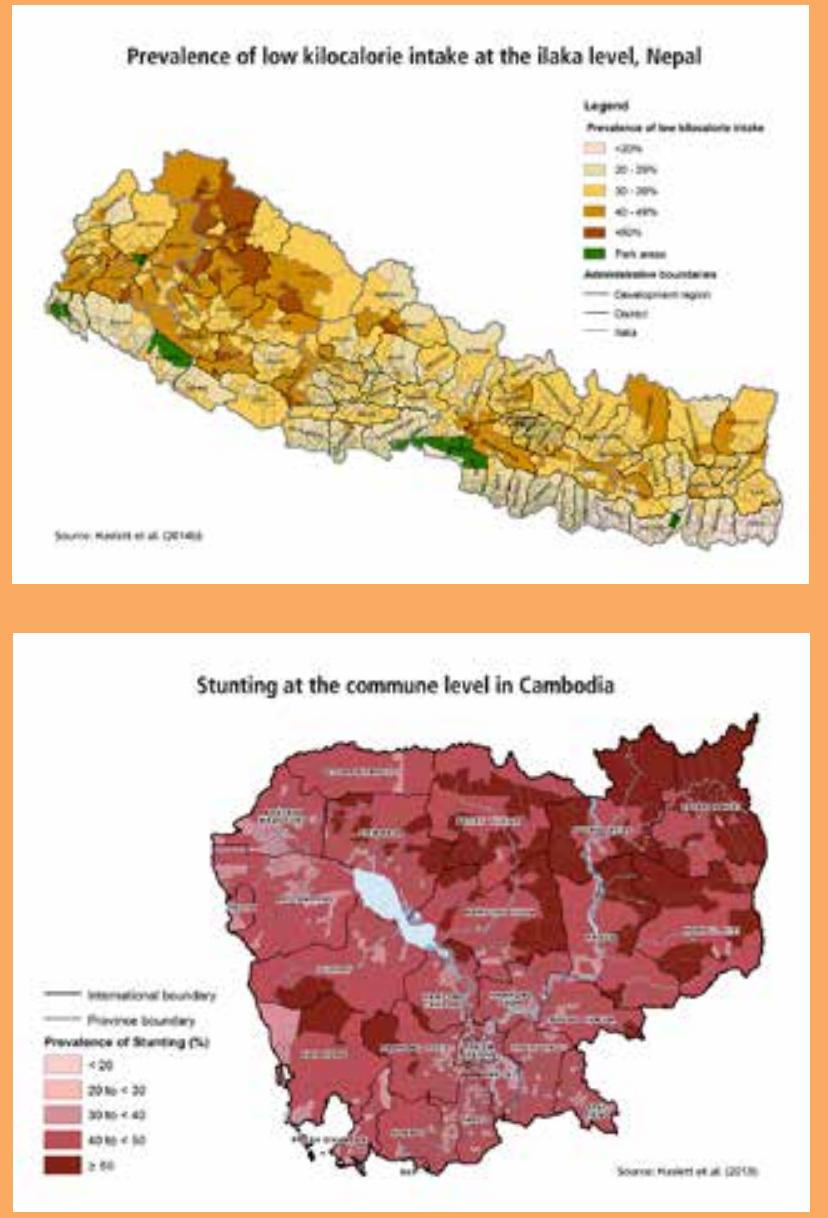

Percentage of stunted children under 5 in Bangladesh, 2012

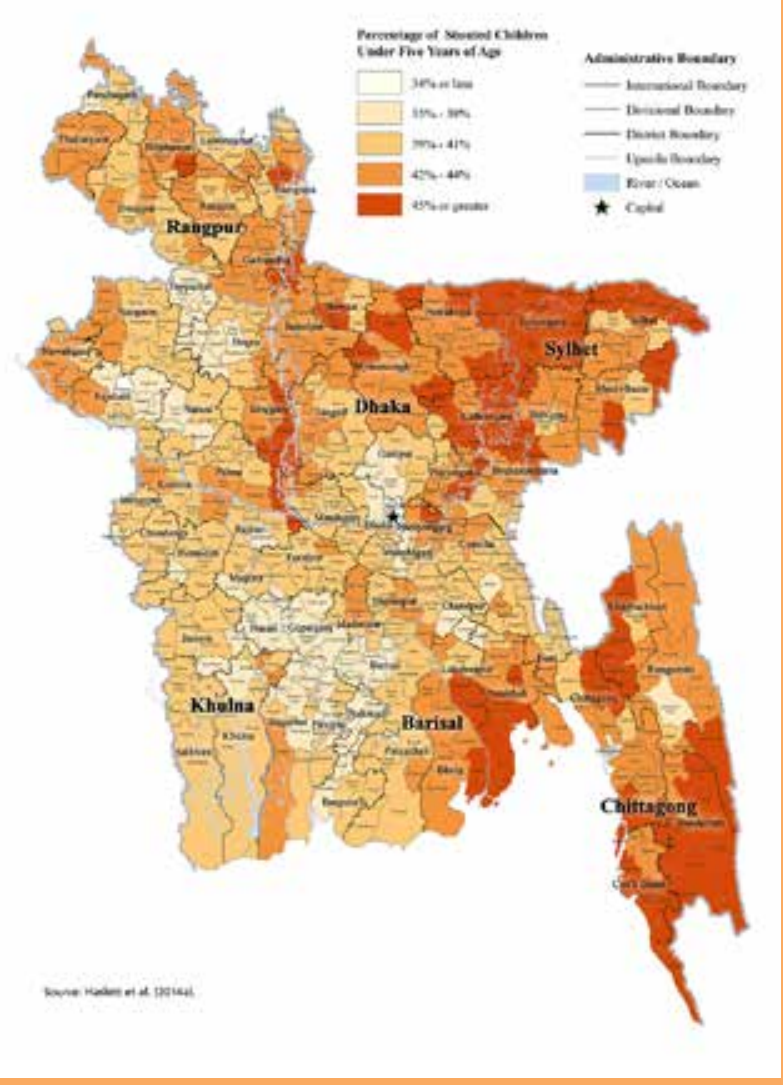


level (for example, the province level) and census data for age-sex-education-urban-rural breakdowns by smaller areas. The method basically attributes the indicator from the province to each of the districts within the province proportionally to the age-sex-education of the districts. Based on the World Food Programme's experience, Panel 8.4 provides a positive assessment of the potential of such maps for highlighting subnational variation in nutrition status.

\section{PROMOTING ACCOUNTABILITY IN CHALLENGING CONTEXTS OF THE HUMANITARIAN SPACE}

As the Global Nutrition Report 2015 reported, extreme poverty is forecast to become more and more concentrated in fragile states; global poverty is declining sharply, but not in the 50 countries that the Organisation for Economic Cooperation and Development (OECD) designates as fragile (Burt et al. 2014). ${ }^{8}$

We do not have enough trend data to be able to replicate this analysis for stunting or wasting. However, Figure 8.11 shows that for the most recent surveys since 2008 the prevalence of stunting and wasting is higher in states that OECD designates as fragile.

Emergencies and humanitarian activity are more likely to occur in these fragile contexts. As the 2015 Global Nutrition Report (Panel 9.8) outlined in its accountability recommendations to the World Humanitarian Summit of 2016, there are many accountability gaps in the humanitarian system.

As part of its humanitarian reform process, the UN initiated the cluster approach in 2005 to improve the effectiveness of humanitarian response through greater predictability, accountability, responsibility, and partnership. ${ }^{9}$ In 2011, the Inter-agency Standing Committee set a framework to guide UN agencies in monitoring accountability to crisis-affected populations. Furthermore, in December 2014, the Core Humanitarian Standard was launched, setting out nine commitments that organizations and individuals involved in humanitarian response can use to improve the quality and effectiveness of the assistance they provide.

Although increasing numbers of humanitarian agencies are engaging in accountability initiatives, there remains a systemwide gap in applying and monitoring such mechanisms in emergency contexts, including for nutrition. In Panel 8.5, the Global Nutrition Cluster team outlines some problems and proposes some solutions. ${ }^{10}$

\section{NUTRITION IN DISPLACED POPULATIONS}

The number of people displaced by war has increased sharply in the past two to three years, with the latest estimate placing it at 59.5 million (Figure 8.12). The refugee population is also at an all-time high of 19.6 million, half of whom are children (Langlois et al. 2016).

Displaced populations are more likely to be vulnerable and marginalized during their flight and within camps, in addition to experiencing the stress and trauma of displacement. They have a high burden of infection and noncommunicable diseases (Gornall 2015; Norredam et al. 2006). Panel 8.6 outlines the challenges of protecting the nutrition status of displaced people and makes some recommendations to strengthen accountability to them, including the need to refine existing mechanisms-and

\section{FIGURE 8.11 Stunting and wasting rates in fragile and nonfragile states}

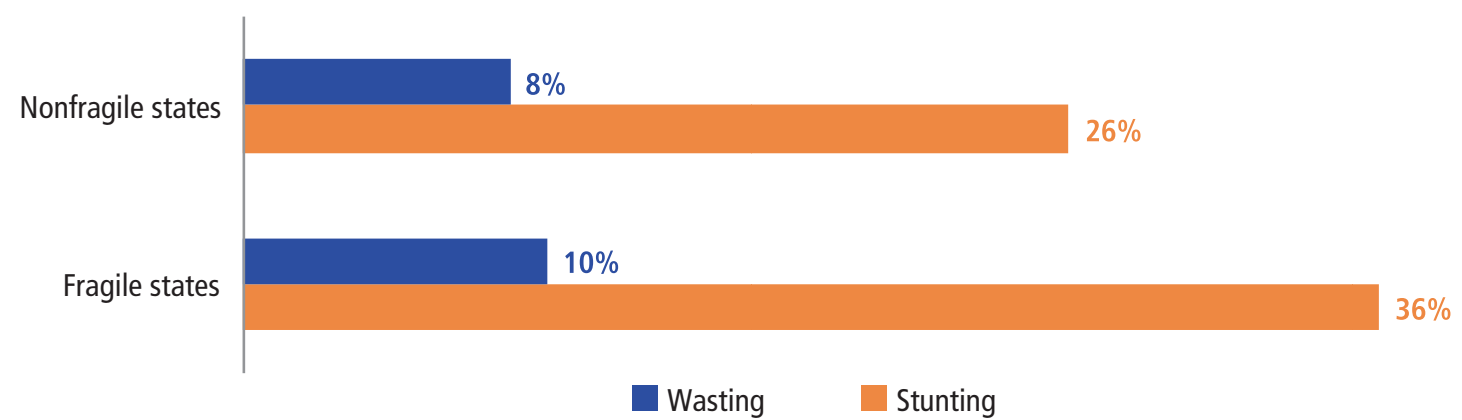

\section{Source: Authors.}

Note: For stunting, $n=104$ of 133 low- and middle-income countries (41/48 fragile, $63 / 85$ nonfragile). For wasting, $n=103$ of 133 low- and middle-income countries (40/48 fragile, 63/85 nonfragile). Data are for the latest survey starting in 2008, and surveys are from 2008 to 2015 . The average year of surveys for fragile and nonfragile countries is virtually identical (2012). 


\section{PANEL 8.5 IMPROVING ACCOUNTABILITY FOR NUTRITION ACTIONS IN EMERGENCY CONTEXTS}

\section{JOSEPHINE IPPE}

$B^{2 a x}$ ased on the experience of the Global Nutrition Cluster, established in 2006 as part of the humanitarian reform process, what is needed to address nutrition accountability within programs in emergency contexts?

1. Invest in technical capacity to scale up nutrition programming in emergency situations. Systematic performance monitoring done in line with Sphere minimum standards (Sphere Project 2016) and other packages, such as the Minimum Reporting Package (Emergency Nutrition Network 2011), has consistently shown poor achievement of targets in the area of infant and young child feeding in emergencies, largely owing to lack of capacity and the low priority donors give this program area. Overall, capacity to scale up a nutrition program in emergency settings remains a problem. Leadership, support for capacity building in technical areas, and operational research on nutrition issues need to be clarified, and accountability for these roles made explicit within the cluster system.
2. Provide incentives to reward partners who meet accountability standards. Although the cluster system clearly articulates the accountability between the cluster lead agency and the humanitarian coordinator, the accountability of the cluster partners is not defined but rather implied within the principle-of-partnership documents. The cluster system is not equipped to redress lack of accountability within a cluster. Additionally, the cluster approach stipulates that where funding and access permit, the cluster lead agency serve as the provider of last resort by filling gaps. This expectation is sometimes unrealistic because of the additional financial resources and capacity required, so an incentive system to reward partners who meet accountability targets or the Core Humanitarian Standards, either by individual donors or through the efforts of the entire humanitarian system, would go a long way in promoting accountability.

3. Ensure that country nutrition plans of action incorporate contingency plans for emergencies and that the capacity to respond to nutritional needs in an emergency is built into these plans. Resources also need to be made available at the national level to promote resilience and ensure a smooth transition from humanitarian response to development.

4. Incorporate nutrition-sensitive interventions in emergency contexts. Increased operational linkages are needed between emergency nutrition interventions and other sectors: water, sanitation and hygiene; health and agriculture; food security; and livelihoods.

5. Establish a common data and accountability platform across partners. In 2015 the Global Nutrition Cluster developed an operational framework and guidance on accountability for nutrition with an aim to establish a common platform across partners. The implementation of operational guidance will ensure that cluster partners address accountability in a measurable way. find new ones - to target food assistance to the most nutritionally and economically vulnerable refugees.

\section{CONCLUSIONS}

Governments, civil society, donors, and nutrition champions from all walks of life measure progress, guide actions, and strengthen accountability by making SMART commitments backed up by data systems that provide credible, useful, and timely information. The data systems need to be focused on nutrition outcomes, but they draw on inputs from a wide range of sectors and data collection mechanisms. They need to focus on the most vulnerable:

\section{FIGURE 8.12 Number of people displaced by war}

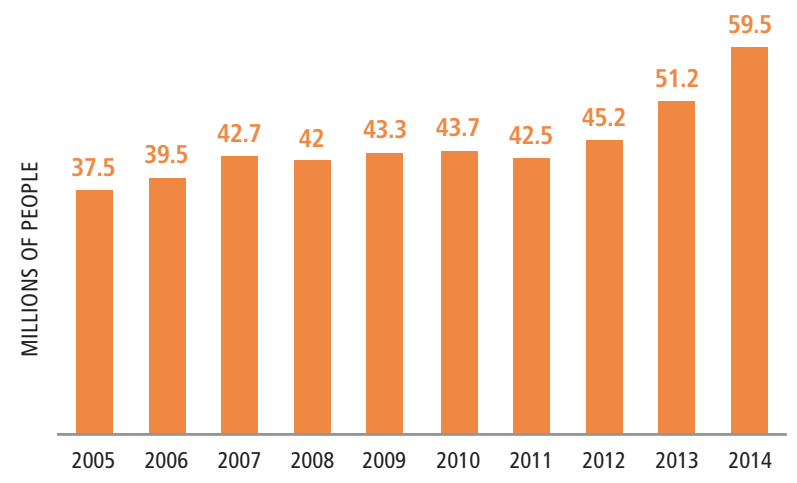

Source: UNHCR (2015) 


\section{PANEL 8.6 PROTECTING THE NUTRITION STATUS OF REFUGEES IN THE SUSTAINABLE DEVELOPMENT GOALS ERA}

\section{CAROLINE WILKINSON, VALERIE GATCHELL, AND PAUL SPIEGEL}

G iven various ongoing conflicts in the Middle East and Africa, the number of forcibly displaced persons has continued to rise throughout 2015 and the beginning of 2016. By the end of 2014, the total population of concern to the UN High Commissioner for Refugees (UNHCR) stood at an unprecedented 55 million persons; this included 14.4 million refugees, 1.8 million asylum seekers, 32.3 million internally displaced persons (IDPs), 3.5 million stateless persons, and 1.8 million returnees.

Refugees are persons outside their country of origin for reasons of fear, persecution, conflict, or generalized violence. The governments of host countries have the primary responsibility for the protection of refugees. UNHCR is mandated to lead and coordinate international action to protect and provide solutions for refugees, asylum seekers (individuals whose refugee status has not yet been determined but who could be eligible to become refugees), stateless people (individuals with no nationality), and returnees (refugees that have returned to their countries of origin). Out of the 12 million refugees for whom information on accommodation type was available, 7.6 million (63 percent) resided in individual accommodation types as opposed to planned/managed or self-settled camps, collective centers, or reception/transit camps. It was estimated that some 6.4 million refugees ( 45 percent) were in protracted situations. ${ }^{1}$

\section{Nutritional Status among Refugees} In 2015, of UNHCR's 93 refugee sites where acute malnutrition was measured (representing approximately 336,000 children 6-59 months old), 54 sites (58 percent) met the UNHCR standards of less than 10 percent global acute malnutrition (GAM), ${ }^{2}$ while 21 sites (22.6 percent) were above the emergency threshold of greater than or equal to 15 percent. Stunting among children 6-59 months met the standard of less than 20 percent in 13 sites (14 percent), whereas 65 sites (69.9 percent) registered stunting prevalence above the critical level of greater than or equal to 30 percent. The prevalence of child anemia met the standard of greater than 20 percent in only 6 of 90 sites (6.7 percent), ${ }^{3}$ and 33 of 90 sites ( 36.7 percent) were under the critical level of less than 40 percent. The majority of sites where data are available across several years show that the prevalence of GAM, stunting, and anemia have been relatively stable (80.6 percent, 66.7 percent, and 59.3 percent, respectively). Significant improvements have been made in reducing GAM and anemia in 14.9 percent and 25.4 percent of sites, respectively. Compared with national statistics (UNICEF 2015), the prevalence of GAM and stunting in refugee sites was higher in $\mathbf{4 8 . 4}$ percent and $\mathbf{5 5 . 9}$ percent, respectively, of the measured sites; anemia data at the national level are unavailable for comparison.

\section{Vulnerability to Food Insecurity and Nutrition}

Because refugees are not citizens of the asylum country, in most cases their legal status is in itself an element of vulnerability. Refugees often have limited or no access to land as well as limited economic rights and freedom of movement. They are often excluded from national social security or safety net mechanisms and often do not have access to national health and nutrition services, where they exist.

Many refugee populations are largely dependent on food assistance provided by the World Food Programme (WFP) (more than 5 million refugees as of February 2016). However, from September 2015 to February 2016, WFP funding shortfalls resulted in food ration cuts to 61 percent of refugees ( 3.4 million) across 20 countries, with additional cuts expected over the coming months. Nutrient-rich and fortified foods are among the first to be cut, owing to their higher costs.

Additionally, a key challenge UNHCR and its partners face is assessing and supporting nutrition and basic services in "out-of-camp" populations, in part because of difficulties in establishing direct contact with refugee populations who are mixed among national populations. In these cases, such as in Jordan, UNHCR works with authorities and partners to facilitate access to national health and nutrition services. Increasingly, UNHCR measures nutritional status among these populations and monitors access to adequate health care.

Continued

those who are in real danger of being left behind because they are excluded from power or lack basic rights. This requires data collected at disaggregated levels: by groups or by region. Collecting such data can be expensive, and so ways need to be found of using existing data (for example, small-area estimation) as well as lower-cost ways of collecting more fine-grained data (for example, using mobile phones). The capacity to analyze and act on such disaggregated data needs to be in place and, to the extent possible, should involve communities themselves in analysis and decision making. The Global Nutrition Report 2014 (Panel 4.3) showed how data disaggregated at the 


\section{PANEL 8.6 PROTECTING THE NUTRITION STATUS OF REFUGEES IN THE SUSTAINABLE DEVELOPMENT GOALS ERA}

\section{CAROLINE WILKINSON, VALERIE GATCHELL, AND PAUL SPIEGEL}

\section{Recommendations}

The 2030 Agenda for Sustainable Development commits to "leave no one behind" in pursuit of ending poverty and promoting peaceful and inclusive societies. It recognizes that refugees, IDPs, and host communities are among the most vulnerable (UNOCHA et al. 2015). To progress on the 2030 agenda for these populations, the international community needs to work collaboratively with governments to do the following:

- Continue to regularly monitor the nutrition (GAM, stunting, and anemia) and food security situation of refugees to foster accountability.

- Strengthen linkages among governments, other UN agencies, and development partners to effectively address stunting and anemia in protracted refugee populations.

- Strengthen coordination among host governments, UNICEF, and UNHCR to ensure availability of basic health, nutrition, and WASH (water, sanitation, and hygiene) services for refugees, IDPs, and host communities, integrating into and supporting national systems whenever possible.

- Further understand reasons behind global food assistance funding deficits and identify predictable funding to ensure an adequate (in quantity and quality) food ration or cash transfer, while continuing to monitor the impact of cuts and refine mechanisms to target food assistance to the most nutritionally and economically vulnerable refugees.

- Support and advocate for the development of legal frameworks that allow refugees the right to work, access to land, and freedom of movement to improve their food security and livelihoods.

The year 2016 provides unprecedented opportunity for raising the profile of nutrition and food insecurity among refugees and other displaced populations, given the World Humanitarian Summit and the UN General Assembly Summit on Refugees and Migrants. Now is the time to collectively advocate and demand coordinated action for improved nutrition and food security for these populations. district level in India could be used to spark dialogue and debate between civil society and district officials about the who, what, why, when, where, how-and how much-of nutrition action.

\section{CALLS TO ACTION}

1. Look well beyond SDG 2 when tracking progress in nutrition: SDG 2 is just the start of nutrition accountability, not the end. Country governments should develop inclusive annual national and subnational reporting mechanisms to assess progress in nutrition outcomes and actions.

\section{Align Demographic and Health Surveys (DHSs)} and Multiple Indicator Cluster Surveys (MICSs) with the SDG indicators for nutrition. In the next 12 months, the implementing and funding partners behind the DHSs and MICSs should work together to identify which SDG indicators can be added to surveys.

\section{Incentivize innovation in nutrition data collection.}

More creative ways to use and collect subnational data are needed. Research funders should stimulate this through innovation prizes. By the end of 2018 a multiyear, multicountry research program on this subject should be announced.

\section{Measure inequalities and honor the SDG} commitment to leave no one behind. Governments, donors, and civil society should do more to identify and address inequalities in nutrition outcomes and access to nutrition services. At a minimum, all new DHS and MICS reports should report on the set of stratifiers we reported on in Chapter 8.

\section{Strengthen nutrition accountability for those} affected by conflicts and emergencies. UN agencies and governments should do more to assess the nutrition status of displaced people and their access to food, care, and health services, and to address gaps therein. Countries vulnerable to emergencies need to do more to incorporate emergency planning into their national nutrition plans. By the end of 2017, as part of the Decade of Action, country governments should consider performing a review of emergency preparedness within their current national nutrition plans. 